\title{
OPTIMIZING FORMULATION OF MINI TABLETS FLOATING RANITIDINE HCL USING FULLY PREGELATINIZED STARCH (MANIHOT ESCULENTA CRANTZ) WITH SIMPLEX LATTICE DESIGN
}

\section{GUSTI NGURAH AGUNG DEWANTARA PUTRA ${ }^{1}$, RETNO MURWANTI ${ }^{2}$, ABDUL ROHMAN ${ }^{3}$, T. N. SAIFULLAH SULAIMAN ${ }^{*}$}

${ }^{1}$ Department of Pharmacy, Faculty of Mathematics and Natural Science, Udayana University, Bali, Indonesia, ${ }^{2}$ Departement of Pharmaceutical Biology, Faculty of Pharmacy, Gadjah Mada University, Yogyakarta, Indonesia, ${ }^{3}$ Departement of Pharmaceutical Chemistry, Faculty of Pharmacy, Gadjah Mada University, Yogyakarta, Indonesia, ${ }^{4}$ Departement of Pharmaceutics, Faculty of Pharmacy, Gadjah Mada University, Yogyakarta, Indonesia

Email: tn.saifullah@gmail.com

Received: 16 Feb 2019, Revised and Accepted: 11 Apr 2019

\section{ABSTRACT}

Objective: The main objective of this study was to optimize the noneffervescent floating mini tablets (NEFT) formula of ranitidine hydrochloride (ranitidine $\mathrm{HCl}$ ) using the simplex lattice design (SLD) with parameters, granule flow rate, hardness, friability, floating lag time and ranitidine $\mathrm{HCl}$ dissolution test (\%).

Methods: The material was prepared using the SLD model was cassava starch fully pregelatinized (CSFP), hydroxypropyl methylcellulose K4M (HPMC K4M), and magnesium stearate. The formula obtained was tested for critical parameters, namely flow rate, hardness, friability, floating lag time and ranitidine $\mathrm{HCl}$ dissolution test (\%). The dissolution test was carried out by using the USP type II method (paddle method). The beaker is immersed in the water bath of temperature $37^{\circ} \mathrm{C}$. It is filled with $900 \mathrm{ml}$ of $0.1 \mathrm{~N} \mathrm{HCl}$, and the apparatus was set at $75 \mathrm{rpm}$. The samples were taken in the interval of $10 \mathrm{~min}$ and estimated content by a spectrophotometer at $312 \mathrm{~nm}$.

Results: The optimum formula based on superimposed graphs of various contour plots with SLD. From the experimental data for all test parameters, the experimental results are approaching with the results of the prediction. The condition for optimum functional components in NEFT was $80 \mathrm{mg}$ for CSFP, HPMC K4M $30 \mathrm{mg}$, and $10 \mathrm{mg}$ magnesium stearate to obtain a yield of $7.85 \mathrm{~kg}$ hardness, $0.34 \%$ friability, $15.27 \mathrm{floating}$ lag time and $91.31 \%$ ranitidine $\mathrm{HCl}$ dissolved.

Conclusion: It can be concluded that the optimum formula using the Design-Expert ${ }^{\circledR}$ program the SLD concept is obtained in the range of 70 -80 mg CSFP, 30-40 mg HPMC K4M, 0-10 mg magnesium stearate.

Keywords: Cassava starch fully pregelatinized, Noneffervescent, Floating mini tablets, Optimization, Simplex lattice design

(C) 2019 The Authors. Published by Innovare Academic Sciences Pvt Ltd. This is an open-access article under the CC BY license (http://creativecommons.org/licenses/by/4.0/] DOI: http://dx.doi.org/10.22159/ijap.2019v11i4.32657

\section{INTRODUCTION}

Amylum as an excipient in pharmaceutical formulations is very widely used because it can be mixed with almost all drugs and is inert without causing chemical reactions [1]. Amylum is often used as an excipient, such as binders. Binder functions to power the mass cohesion of powder at press time. Binding materials influence the dissolution rate of the drug [2]. The more strongly bound an active substance is with excipients and will not be able to dissolve in the body, and not achieve the expected bioavailability [3-5].

Amylum is a reserve polysaccharide that is abundant in plants. In general, starch consists of water-soluble components (amylose) as much as $20 \%$ and water-insoluble parts (amylopectin) as much as $80 \%$ [6]. Amylose is a straight molecule, consisting of 250-300 Dglucose units and is uniformly linked by $\alpha$-1,4-glucoside bonds, which tends to cause the molecule to be shaped like a helix [7-9] Amylopectin consists of 1,000 or more glucose units, most of which is also associated with $\alpha-1.4$ bonds. However, there are also a number of $\alpha-1.6$ bonds found at the branching points [10, 11]. This number of bonds are approximately $4 \%$ of the total number of relationships or one for every 25 glucose units. Amylopectin in water can form colloidal solutions $[12,13]$. When the colloidal solution is heated a sticky period occurs, this property is used as a binder. Amylose has the ability to expand when in contact with liquids, this property is used as a destroyer [14-16].

Modification of the physical properties of starch was carried out in a pregelatinized manner. The purpose of this modification is to improve the flow properties and its compatibility so that it can be used as a binder in printed tablets directly and can reduce glidan and antiadherent use [17]. The use of glidan and antiadherent can extend dissolution rates because it can form a film layer [18].
Modification of pregelatinized starch was carried out by giving the treatment in the form of adding the right amount of water and heating at the appropriate temperature. This method produces starch with larger particle size and higher particle density [19]. In pregelatinized starch due to the addition of proper water and heating, a gel formation process causes the starch granules to absorb water and expand to form a thick mass [20].

One of the local plants producing starch that can be modified in this way is cassava amylum. In addition to its relatively cheap price, cassava amylum is relatively easy to obtain, so it is potential to be used as a solid dosage excipient [21]. Amylopectin content is high, which is equal to $83 \%$, making cassava starch potential to be used as a binder in the manufacture of pharmaceutical preparations [22]. The aim of the study was to optimize the NEFT formula of ranitidine $\mathrm{HCl}$ using the CSFP base on SLD design.

\section{MATERIALS AND METHODS}

\section{Materials}

The study used tubers of cassava (Manihot esculenta Crantz) as the basic ingredient to make starch. The cassava was obtained from Banyuning Village in Bali, Indonesia. The botanical identity of the plant and determination already done in the Eka Karya Bali plant conservation center, voucher specimen number B-451. The starch was prepared using fully pregelatinized methods [23], with the addition of distilled water and then heating above the starch gelatinating temperature, ranitidine $\mathrm{HCl}$ (Chemo Lugano), HPMC $\mathrm{K} \mathrm{M}^{\circledR}$ (Colorcon), magnesium stearate, all ingredients mentioned have pharmaceutical qualities. Sodium chloride, methanol (Merck p. a), distilled water, aquabides, acetonitrile (Merck p. a), and raw material ranitidine $\mathrm{HCl}$ (catalog number 66357-59-3 SIGMA). 


\section{Instrumentation and software}

Tablet machine (Korsh ${ }^{\circledR}$ USA single punch), JASCO FT-IR-4200 type A model, Electromagnetic Sieve Shaker EMS-8, Electrolab Tap density tester EDT-1020, Oakton pH 510 series, oven, Erweka Type TA/TR 120, Erweka Disintegrator tester ZT X20, Electrolab Dissolution tester (USP) TDL-08L, and UV-Vis spectrophotometry (Genesys). DoE was computed and analyzed applying DesignExperts ${ }^{\circledR}$ software 7.1.5 (computer lab Gadjah Mada University).

\section{CSFP preparation}

The CSFP was made with a starch: distilled water ratio of $1: 1(\mathrm{w} / \mathrm{v})$. The mixture was then stirred until a homogenous suspension was formed. The suspension was heated with water vapour at a temperature $80^{\circ} \mathrm{C}$ in a drum, which was closed for $15 \mathrm{~min}$, until gelatinization occurred. The pregelatinized starch was then dried in an oven at $50{ }^{\circ} \mathrm{C}$ or $48 \mathrm{~h}$. Once dried, it was sieved using a 20-mesh sieve [24-26].

\section{Preparation of granules}

The wet granulation method of massing and screening was used 150 $\mathrm{g}$ batches of formulated mixtures of ranitidine $\mathrm{HCl}$, CSFP, HPMC $\mathrm{K} 4 \mathrm{M}$, and magnesium stearate were mixed [27]. In small batches the ingredients may be mixed in stainless steel bowls or mortars. They were then moistened with polyvinylpyrrolidone K 30 (PVP K-30) binder solution to yield $2 \% \mathrm{w} / \mathrm{w}$, PVP in the final dried granulation. The resulting wet masses were granulated by passing them manually through a 10 mesh sieve, dried oven at $50{ }^{\circ} \mathrm{C}$ for $7 \mathrm{~h}$, and then re-sieved through a 20 mesh sieve. The dried granules were lubricated by using magnesium stearate [28-30].

\section{Preparation of NEFT}

Quantities (150 g) of granules from each batch were compressed into tablets with predetermined loads on single tablet press with a $8 \mathrm{~mm}$ die and flat faced punch assembly. A set of tablets was produced from each pressure. After ejection, the tablets were stored in airtight containers to allow for elastic recovery and hardening, prevent falsely low yield values before the tablets were subjected to analysis [31,32].

\section{Dissolution test}

The dissolution test was carried out by using the USP type II method (paddle method). The beaker is immersed in the water bath of temperature $37^{\circ} \mathrm{C}$. It is filled with $900 \mathrm{ml}$ of $\mathrm{HCl} 0.1 \mathrm{~N}$ and the apparatus was set at $75 \mathrm{rpm}$. The samples were taken in an interval of $10 \mathrm{~min}$ and estimate the content by spectrophotometer at $312 \mathrm{~nm}$. The same procedure was repeated at different time intervals and absorbance was noted and the percentage drug release was calculated [33, 34].

\section{Formula design according to SLD}

Based on the Design-Expert $(\circledR$ version 7.1.5, for the optimization method with SLD, with 3 independent variables (mixture of 3 components) 14 experiments were conducted on various mixed compositions for the three components, there are repetitions of several formulas according to those suggested by the Design-Expert@ program [35, 36].

In this study, the variables to be optimized are CSFP (X1), HPMC K4M (X2) and magnesium Stearate (X3). The total mixture of X1+X2+X3 for each formula was $120 \mathrm{mg}$, with a total weight of $150 \mathrm{mg}$ mini tablets containing $33,48 \mathrm{mg}$ ranitidine $\mathrm{HCl}$. Determination of the minimum and maximum limits for the three components optimized based on the results of the literature study and preliminary research $[37,38]$.

The SLD was used to optimize the NEFT formula for ranitidine $\mathrm{HCl}$ tablets with variations in the levels of CSFP 70-80 mg, and HPMC K4M 30-40 mg, magnesium stearate 0-10 mg. The optimum formula using the Design-Expert ${ }^{\circledR}$ program is based on parameters: granule flow rate, hardness, friability, floating lag time, and ranitidine $\mathrm{HCl}$ dissolution test (\%) [39].

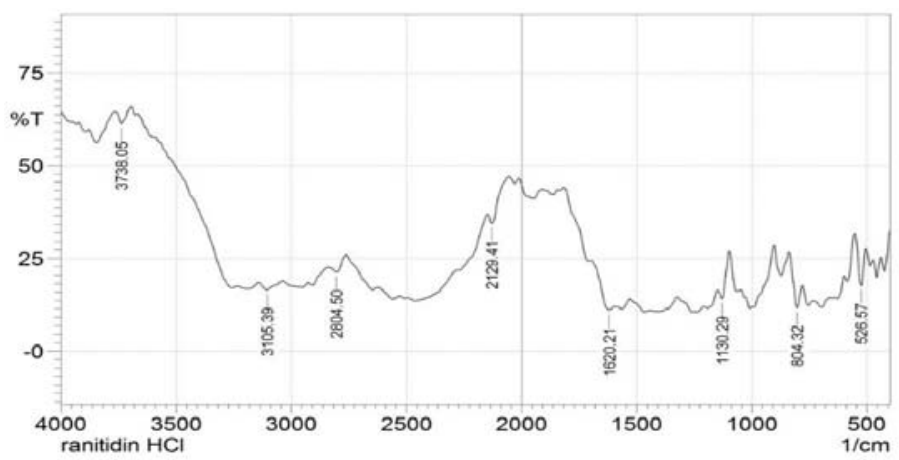

Fig. 1:Fourier transform infrared (FT-IR) spectroscopy analysis of ranitidine $\mathrm{HCl}$

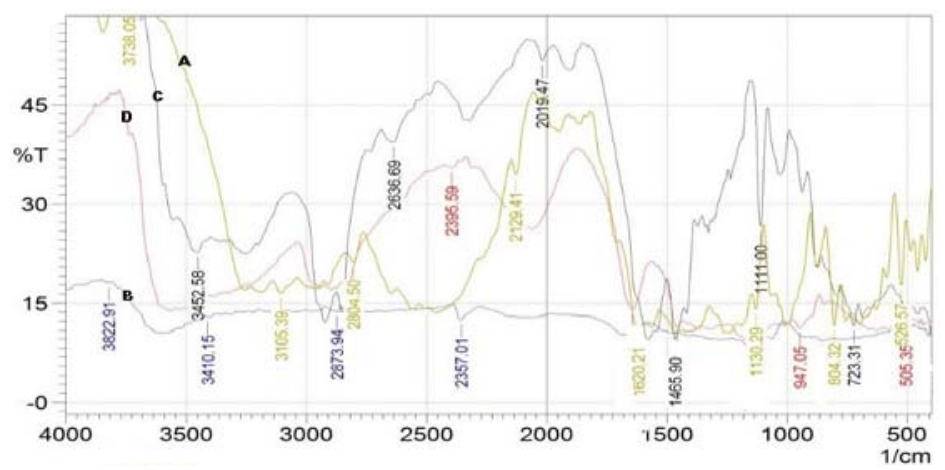

Fig. 2:Overlay ranitidine $\mathrm{HCl}+\mathrm{CSFP}+$ magnesium stearate+HPMC K4M, Where: A: ranitidine HCl, B: CSFP, C: magnesium stearate, D: HPMC K4M

\section{RESULTS AND DISCUSSION}

\section{Interaction study of ranitidine $\mathrm{HCl}$ with excipients in formulas}

By comparing the spectrum of single ranitidine $\mathrm{HCl}$, a mixture of ranitidine $\mathrm{HCl}$ and CSFP and a mixture of ranitidine $\mathrm{HCl}$ with components present in the tablet gastroretentive formula (fig. 1 and fig. 2), it can be concluded that there is no chemical interaction (no chemical incompatibility) between components in the formula. The IR spectra showed that there was no chemical interaction that caused the formation of a bond between ranitidine $\mathrm{HCl}$ and 
excipients in the formula. The presence of a new peak and loss of the original peak, indicates an interaction. [40]. Ranitidin $\mathrm{HCl}$ is incompatible with lactose fillers, PVP (polivinil pirolidone) polymers and there is mild interaction with eudragit E100 [41].

\section{Simplex lattice design}

The SLD was used to optimize the NEFT formula for ranitidine $\mathrm{HCl}$ tablets with variations in the levels of CSFP $70-80 \mathrm{mg}$, and HPMC K4M 30-40 mg, magnesium stearate 0-10 mg. The optimum formula using the Design-Expert ${ }^{\circledR}$ program (table 1.)

\section{Flow properties}

Material flow properties can be illustrated with parameters of flow velocity and angle of repose. The pregelatinized fully produced starch can flow through the funnel with a flow rate for $100 \mathrm{~g}$ less than $10 \mathrm{~s}$. At the parameters of flow velocity, CSFP has a flow rate of $6.23 \mathrm{~s}$, while for the parameters of the angle of repose, and has an angle of repose of 32.570 . This indicates that the modified material of the starch produced better flow properties.

From the data of the flow velocity test from all runes with the ANOVA test, the p-value value obtained with a $95 \%$ significance level obtained the value of $0.0004(<0.05)$. The p-value value with the quadratic model is lower than 0.05 , indicating that there are significant differences in flow velocity due to the use of the three optimized ingredients. The lack of fit analysis with the results of the p-value of $0.0806(>0.05)$ with a confidence level of $95 \%$, shows that there is no significant difference between the experimental data and the predicted data from the suggested model (table 2)

Table 1: Proportion of each component according to the SLD

\begin{tabular}{|c|c|c|c|}
\hline \multirow[t]{2}{*}{ Trial code } & \multicolumn{3}{|c|}{ Material (mg)/mini tablet } \\
\hline & CSFP & HPMC K4M & Magnesium stearate \\
\hline 1 & 76.67 & 36.67 & 6.67 \\
\hline 2 & 80 & 40 & 0 \\
\hline 3 & 78.33 & 33.33 & 8.33 \\
\hline 4 & 75 & 35 & 10 \\
\hline 5 & 80 & 35 & 5 \\
\hline 6 & 80 & 40 & 0 \\
\hline 7 & 80 & 30 & 10 \\
\hline 8 & 80 & 30 & 10 \\
\hline 9 & 70 & 40 & 10 \\
\hline 10 & 70 & 40 & 10 \\
\hline 11 & 75 & 40 & 5 \\
\hline 12 & 78 & 38.33 & 3.33 \\
\hline 13 & 75 & 35 & 10 \\
\hline 14 & 73.33 & 38.33 & 8.33 \\
\hline
\end{tabular}

${ }^{*}$ Formula using the Design-Expert ${ }^{\circledR}$ program the SLD concept

Table 2: Analysis of variance (ANOVA) of the flow properties

\begin{tabular}{llllll}
\hline Source & Sum of squares & df & Mean square & F Value & p-value prob>F \\
\hline Model & 45.08 & 5 & 9.02 & 17.16 & 0.0004 \\
Linier mixture & 32.1 & 2 & 16.05 & 30.54 & 0.0002 \\
AB & 0.56 & 1 & 0.56 & 1.06 & 0.3341 \\
AC & 0.55 & 1 & 0.56 & 1.05 & 0.3345 \\
BC & 12.28 & 1 & 12.28 & 23.37 & 0.0013 \\
Residual & 4.2 & 8 & 0.53 & & 0.0806 \\
Lack of fit & 3.47 & 4 & 0.87 & 4.74 & Not significant \\
Pure error & 0.73 & 4 & 0.18 & & \\
Cor total & 49.29 & 13 & & & \\
\hline
\end{tabular}

*The p-value value indicating that there are significant differences in flow velocity due to the use of the three optimized ingredients. The values are mean \pm standard deviation of $n=5$.

From the data of the flow velocity ready for the press, the equation according to the SLD is obtained as follows:

Flow rate $(\mathrm{g} / \mathrm{s})=-0,045(\mathrm{~A})+2,36(\mathrm{~B})+2,71(\mathrm{C})-0,024(\mathrm{~A})(\mathrm{B})+0,029$ (A) (C) $-0,14$ (B) (C)

Where:

$A=$ starch component fraction CSFP

$B=$ fraction of HPMC K4M components

$\mathrm{C}=$ fraction of the Magnesium stearate component

From the equation, it can be seen that the starch matrix component is fully pregelatinized, HPMC K4M and magnesium stearate and component interactions, influence the flow velocity. Individually CSFP has a negative effect, which means it can reduce flow velocity. For HPMC K4M and magnesium stearate individually, it is positive, which means it can increase flow speed. While the optimized two-component interaction of CSFP with HPMC K4M and HPMC K4M with magnesium stearate has a negative effect which means it can reduce flow velocity, while the interaction between CSFP with magnesium stearate has a positive effect which means it can increase flow speed.

\section{Hardness test}

For each formulation, the hardness of the tablets was determined individually using a hardness tester. The batch of all batches was found $8.52+0.231 \mathrm{~kg}$.

From the hardness test data from all runes with the ANOVA test, the p-value value obtained with a $95 \%$ significance level obtained a value of $0.002(<0.05)$. The $p$-value value with the quadratic model is lower than 0.05 , indicating that there are significant differences in flow velocity due to the use of the three optimized ingredients.

The lack of fit analysis with the results of the p-value $0.0879(>0.05)$ with a confidence level of $95 \%$, shows that there is no significant difference between the experimental data and the predicted data from the suggested model (table 3). 
Table 3: Analysis of variance (ANOVA) of the hardness test

\begin{tabular}{llllll}
\hline Source & Sum of squares & df & Mean square & F value & p-value prob>F \\
\hline Model & 7.88 & 5 & 1.57 & 11.05 & 0.002 \\
Linier mixture & 4.36 & 2 & 2.18 & 15.34 & 0.0018 \\
AB & 2.47 & 1 & 2.47 & 17.4 & 0.0031 \\
AC & 1.01 & 1 & 1.01 & 7.11 & 0.0288 \\
BC & 0.025 & 1 & 0.025 & 0.18 & 0.0058 \\
Residual & 1.14 & 8 & 0.14 & 4.48 & 0.0879 \\
Lack of fit & 0.93 & 4 & 0.23 & & Not significant \\
Pure error & 0.21 & 4 & 0.052 & & \\
Cor total & 0.99 & 13 & & \\
\hline
\end{tabular}

*The p-value value indicating that there are significant differences in flow velocity due to the use of the three optimized ingredients. The values are mean \pm standard deviation of $n=5$.

From the data on tablet hardness, the equation according to the SLD is obtained as follows:

Hardness $(\mathrm{g} / \mathrm{s})=-0.82(\mathrm{~A})-2.28(\mathrm{~B})-1.20(\mathrm{C})+0.05(\mathrm{~A})(\mathrm{B})+0.04(\mathrm{~A})(\mathrm{C})-$ $6,23(\mathrm{~B})(\mathrm{C})$

Where:

A = starch component fraction fully pregelatinized

$\mathrm{B}=\mathrm{HPMC} \mathrm{K} 4 \mathrm{M}$ component fraction

$\mathrm{C}=$ fraction of the Magnesium stearate component

From the equation, it can be seen that the starch matrix component is fully pregelatinized, HPMC K4M and magnesium stearate and component interactions, influence the hardness. Individually the starch is fully pregelatinized, HPMC K4M, and magnesium stearate has a negative effect, which means it can reduce violence. While the optimized two-component interaction, which is CSFP with HPMC K4M and CSFP with magnesium stearate, has a positive effect which means it can increase hardness, while the interaction between HPMC K4M and magnesium stearate has a negative effect which means it can reduce violence. In fig. (fig. 5B), for the red area to get the optimum formula.

\section{Tablet friability}

According to the USPNF23, 10 tablets were randomly selected and placed in the drum of a tablet friability test apparatus. The drum was adjusted to rotate 100 times in 4 min then the tablets were removed from the drum, dedusted, and accurately weighed. The percent weight loss was calculated. The friability test of tablets of entire batches. Depicted that the tablets of entire batches had passed the USP criteria of variability testing (0.5-1 $\%$, w/w). The results revealed that tablets possess good mechanical strength.

From friability testing data from all runes with ANOVA test, pvalue obtained with a significance level of $95 \%$ obtained a value of $0.0046(<0.05)$. The p-value value with the quadratic model is lower than 0.05 , indicating that there are significant differences in probability tests due to the use of the three optimized ingredients.

The lack of fit analysis with the results of the p-value of 0.0786 $(>0.05)$ with a confidence level of $95 \%$, indicates that there is no significant difference between the experimental data and the predicted data from the suggested model (table 4).

Table 4: Analysis of variance (ANOVA) of the friability test

\begin{tabular}{llllll}
\hline Source & Sum of squares & df & Mean square & F value & p-value prob $>$ F \\
\hline Model & 5.261 & 5 & 1.05 & 8.52 & 0.0046 \\
Linier mixture & 3.52 & 2 & 1.76 & 1.43 & 0.2947 \\
AB & 1.032 & 1 & 1.03 & 0.84 & 0.3874 \\
AC & 4.5 & 1 & 4.5 & 36.51 & 0.0003 \\
BC & 5.864 & 1 & 5.86 & 4.75 & 0.061 \\
Residual & 9.88 & 8 & 1.23 & 4.81 & 0.0786 \\
Lack of fit & 8.18 & 4 & 2.04 & & Not significant \\
Pure error & 1.7 & 4 & 4.25 & & \\
Cor total & 6.24 & 13 & & \\
\hline
\end{tabular}

*The p-value value indicating that there are significant differences in probability tests due to the use of the three optimized ingredients. The values are mean \pm standard deviation of $n=5$.

From the data friability of the tablet, the equation according to the SLD is obtained as follows:

Friability (\%) $=7.87(\mathrm{~A})+1.16(\mathrm{~B})+0.05(\mathrm{C})-1.05(\mathrm{~A})(\mathrm{B})-8.36(\mathrm{~A})$ (C) $+3,014(\mathrm{~B})(\mathrm{C})$

Where:

A = starch component fraction fully pregelatinized

$\mathrm{B}=$ HPMC K4M component fraction

$\mathrm{C}=$ fraction of the Magnesium stearate component

From the equation, it can be seen that the starch matrix component is fully pregelatinized, HPMC $\mathrm{K} 4 \mathrm{M}$ and magnesium stearate and component interactions, have an effect on variability. Individually the starch is fully pregelatinized, HPMC K4M, and magnesium stearate has a positive effect, which means it can improve friability.
While the optimized two-component interaction, which is CSFP with HPMC K4M and CSFP with magnesium stearate, has a negative effect which means it can reduce friability, while the interaction between HPMC K4M and magnesium stearate has a positive effect which means it can improve friability.

\section{Floating lag time \\ Comparison of excipients}

The floating tablets were prepared by wet granulation. Each tablet contained ranitidine $\mathrm{HCl}$ (33.4 mg), matrix-forming polymers $30 \mathrm{mg}$ (different grades of HPMC) combination with CSFP ( $80 \mathrm{mg}$ ) and magnesium stearate $(10 \mathrm{mg})$. Different grades of HPMC are HPMC K100LV combination with CSFP, HPMC K4M combination with CSFP, HPMC K15M combination with CSFP. The results showed that the HPMC K4M combination with CSFP could provide immediate floatation upon contact with the dissolution medium and were able to continuously float over $24 \mathrm{~h}$ (table 5). 
Table 5: Floating lag time

\begin{tabular}{ll}
\hline Comparison of excipient & Floating lag time (min)+SD \\
\hline HPMC K4M combination with CSFP & $15.304+0.089$ \\
HPMC K100LV combination with CSFP & $16.402+0.085$ \\
HPMC K15M combination with CSFP & $23.874+1.706$ \\
\hline
\end{tabular}

*HPMC K4M combination with CSFP could provide immediate floatation upon contact with the dissolution medium. The values are mean \pm standard deviation of $n=5$.

Floating lag time describes the time needed by the tablet when it starts to be inserted into the test medium until the tablet floats. Floating time parameters are very important for gastroretentive tablet preparations with floating systems. The results of the literature study do not yet have information about what is the best floating lag time for gastroretentive tablets. The results of the study show that gastroretentive tablets have a floating time of 13$32 \mathrm{~min}$.

The results of testing for flotation for up to $24 \mathrm{~h}$ of observations, the tablet is still floating. The tablet floats because the starch is fully pregelatinized by the medium and causes the tablet to expand, and the gel is formed by the presence of the HPMC K4M matrix in tablet formulas so as to maintain the integrity of the tablet.

From the floating lag time test data from all runs with the ANOVA test, the p-value value obtained with a $95 \%$ significance level obtained a value of $0.0318(<0.05)$. The $p$-value value with the quadratic model is lower than 0.05 , indicating that there are significant differences in flow velocity due to the use of the three optimized ingredients.

The lack of fit analysis with the results of p-value $0.0746(>0.05)$ with a confidence level of $95 \%$, shows that there is no significant difference between the experimental data and the predictive data from the suggested model (table 6).

Table 6: Analysis of variance (ANOVA) of the floating lag time test

\begin{tabular}{llllll}
\hline Source & Sum of squares & df & Mean square & F value & p-value prob>F \\
\hline Model & 469.12 & 5 & 93.62 & 4.4 & 0.0318 \\
Linier mixture & 215.4 & 2 & 107.7 & 5.05 & 0.0381 \\
AB & 241.31 & 1 & 241.31 & 11.32 & 0.0099 \\
AC & 11.34 & 1 & 11.34 & 0.53 & 0.4866 \\
BC & 1.73 & 1 & 1.73 & 0.081 & 0.7828 \\
Residual & 170.52 & 8 & 21.31 & 4.98 & 0.0746 \\
Lack of fit & 142 & 4 & 35.5 & & Not significant \\
Pure error & 28.52 & 4 & 7.13 & & \\
Cor total & 639.64 & 13 & & & \\
\hline
\end{tabular}

*The $\mathrm{p}$-value value with the indicating that there are significant differences in flow velocity due to the use of the three optimized ingredients. The values are mean \pm standard deviation of $n=5$.

From the floating lag time tablet data, the equation according to the SLD is as follows:
Floating lag time $(\mathrm{min})=-7.27$
$\begin{array}{lll}(A)-25.47 & (B)+4.62 \quad(C)+0.51\end{array}$
$(\mathrm{A})(\mathrm{B})+0.13(\mathrm{~A})(\mathrm{C})-0,052(\mathrm{~B})(\mathrm{C})$

Where:

$A=$ starch component fraction fully pregelatinized

$\mathrm{B}=$ HPMC K4M component fraction

$\mathrm{C}=$ fraction of the Magnesium stearate component
From the equation, it can be seen that the starch matrix component is fully pregelatinized, HPMC K4M and magnesium stearate and component interactions, have an effect on friability. Individualism CSFP has a negative effect, while HPMC K4M, and magnesium stearate have a positive effect, which means it can increase the floating lag time. While the optimized two-component interaction, which is CSFP with HPMC K4M and CSFP with magnesium stearate, has a positive effect which means it can increase the floating lag time, while the interaction between HPMC K4M and magnesium stearate has a negative effect, which can reduce the floating lag time.

\section{Dissolution test}

Validation method

Table 7: Analysis LOD and LOQ

\begin{tabular}{|c|c|c|c|c|}
\hline Concentration & Absorbancy (y) & $y^{\prime}$ & $y^{\prime}-y$ & $\left(y^{\prime}-y\right) 2$ \\
\hline 10 & 0.461000 & 0.466400 & 0.005400 & 0.000029 \\
\hline 12 & 0.558000 & 0.547400 & -0.010600 & 0.000112 \\
\hline 13 & 0.592000 & 0.587900 & -0.004100 & 0.000017 \\
\hline 14 & 0.615000 & 0.628400 & 0.013400 & 0.000180 \\
\hline 15 & 0.671000 & 0.668900 & -0.002100 & 0.000004 \\
\hline 17 & 0.752000 & 0.749900 & -0.002100 & 0.000004 \\
\hline \multirow[t]{5}{*}{18} & 0.789000 & 0.790400 & 0.001400 & 0.000002 \\
\hline & & & $\Sigma$ & 0.000349 \\
\hline & & & Sy/x & 0.008351 \\
\hline & & & LOD & 0.592247 \\
\hline & & & LOQ & 1.974158 \\
\hline
\end{tabular}




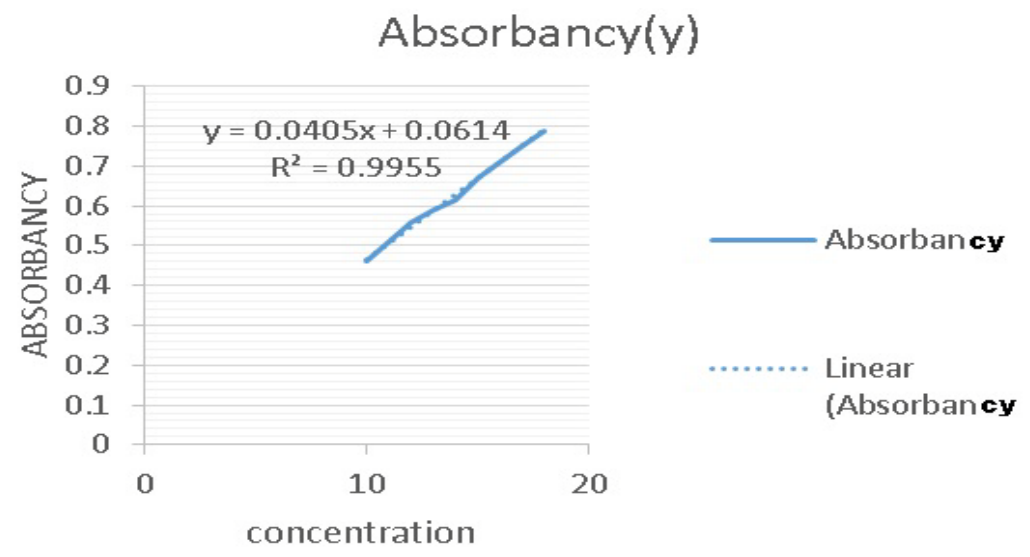

Fig. 3:The curve of ranitidine $\mathrm{HCl}$ in $0.1 \mathrm{~N} \mathrm{HCl}$ dissolution medium

The maximum wavelength of ranitidine $\mathrm{HCl}$ was obtained in $0.1 \mathrm{~N}$ $\mathrm{HCl}$ medium at $312 \mathrm{~nm}$. The linear regression equation obtained $\mathrm{y}=$
$0.0405 \mathrm{X}+0.0614(\mathrm{Y}=$ absorbancy and $\mathrm{X}=$ ranitidine $\mathrm{HCl}$ content $)$ with a correlation coefficient of 0.9955

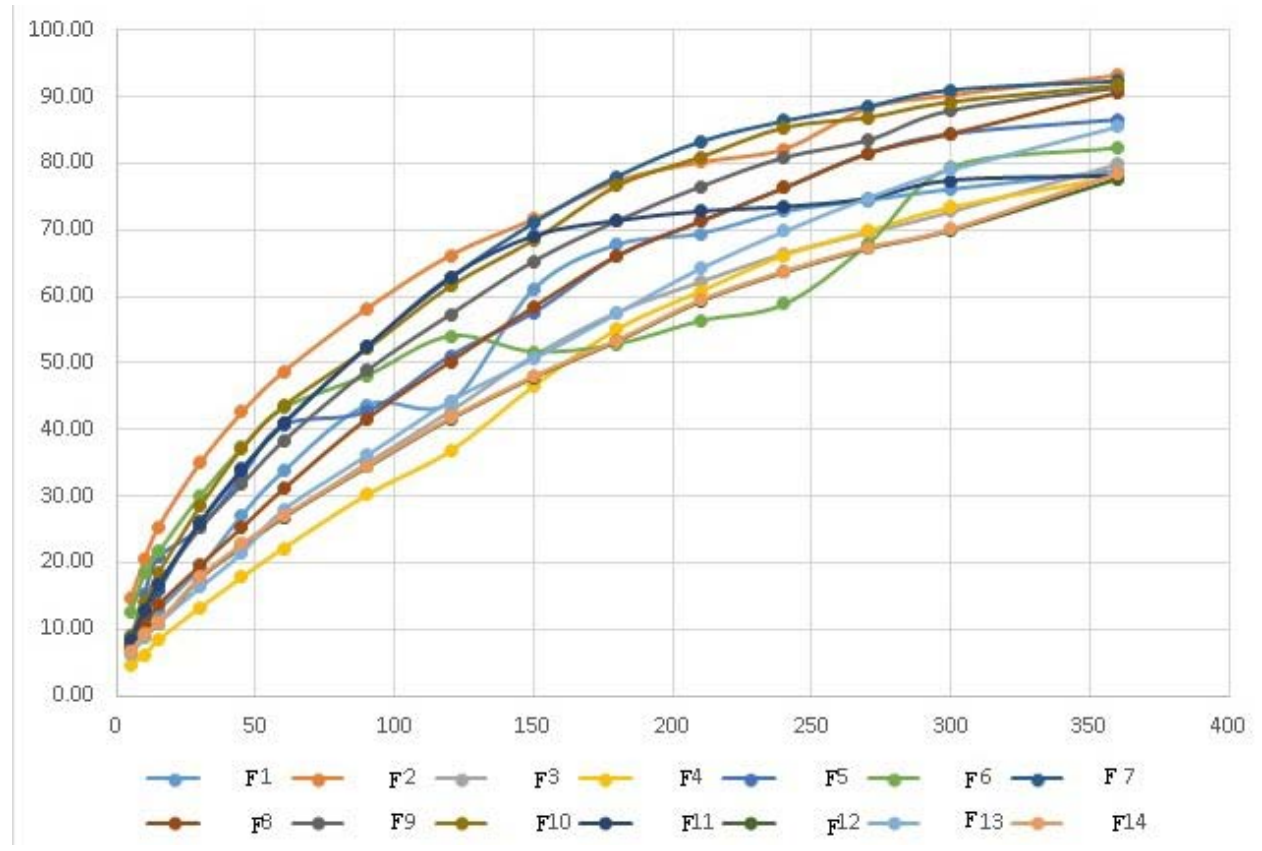

Fig. 4:Profil average dissolved of ranitidine $\mathrm{HCl}$ in the $\mathrm{HCl} 0.1 \mathrm{~N}$, the values are mean \pm standard deviation of $\mathrm{n}=5$

Table 8: Analysis of variance (ANOVA) of the dissolved of ranitidine $\mathrm{HCl}$ in the $\mathrm{HCl} 0.1 \mathrm{~N}$

\begin{tabular}{lllllll}
\hline Source & Sum of squares & df & Mean square & F value & p-value prob>F & significant \\
\hline Model & 390.23 & 5 & 78.05 & 5.63 & 0.0162 & \\
Linier mixture & 15.03 & 2 & 7.52 & 0.54 & 0.0016 & \\
AB & 162.29 & 1 & 162.29 & 11.7 & 0.0091 & \\
AC & 172.59 & 1 & 172.59 & 12.44 & 0.0078 & not significant \\
BC & 23.37 & 1 & 23.37 & 1.68 & 0.2304 & \\
Residual & 110.97 & 8 & 13.87 & & & \\
Lack of fit & 22.7 & 4 & 5.68 & 0.26 & & \\
Pure error & 88.27 & 4 & 22.07 & & & \\
Cor total & 501.2 & 13 & & & & \\
\hline
\end{tabular}

*The release profile of ranitidine $\mathrm{HCl}$ from a tablet has a similar profile, which is slow release. The values are mean \pm standard deviation of $\mathrm{n}=5$.

Abbreviations: F: formulations.

Fig. 4 shows that the release profile of ranitidine $\mathrm{HCl}$ from a tablet has a similar profile, which is a slow release. In the initial phase until the 60 th $\mathrm{min}$, the release is still quite large and is followed by slower release until it reaches steady state.
From the data of ranitidine $\mathrm{HCl}$ dissolved (\%), the equation obtained:

Ranitidine $\mathrm{HCl}$ dissolved $(\%)=7.39(\mathrm{~A})+20.88(\mathrm{~B})+34.84(\mathrm{C})-0.42(\mathrm{~A})$

(B) $-0.52(\mathrm{~A})(\mathrm{C})-0.19(\mathrm{~B})(\mathrm{C})$

Where: 
$A=$ starch component fraction fully pregelatinized

$\mathrm{B}=$ HPMC K4M component fraction

$\mathrm{C}=$ fraction of the Magnesium stearate component

ANOVA results of the quadratic model, the calculated probability value $(p$-value $)=0.0162$. The calculated $p$-value is less than 0.05 indicating the model/equation obtained is significant (model fit) at the $95 \%$ confidence level. The equation model obtained can be used to navigate the design space.

From the above equation shows that each component individually has a positive effect which means it can increase dissolitidine $\mathrm{HCl}$ dissolved (\%). Two-component interaction produces a coefficient that is negative, which means it can reduce the speed of release.

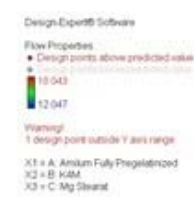

A
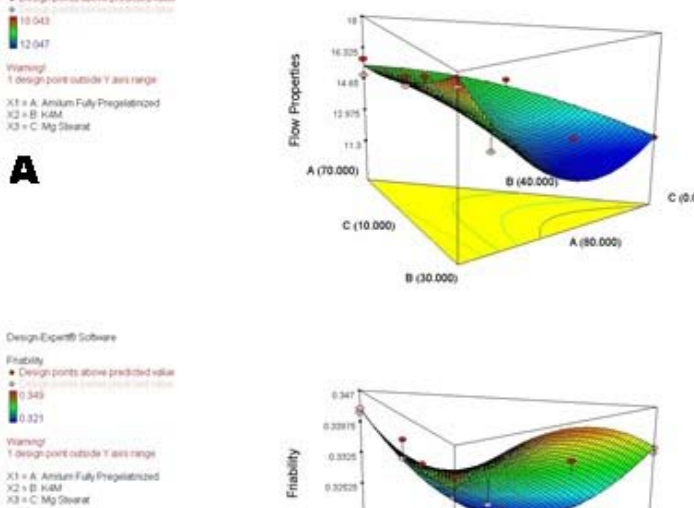

C
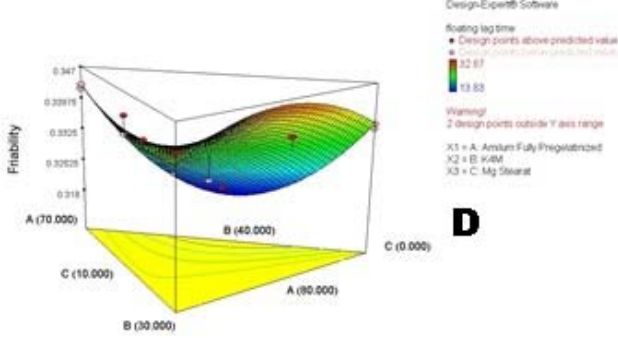
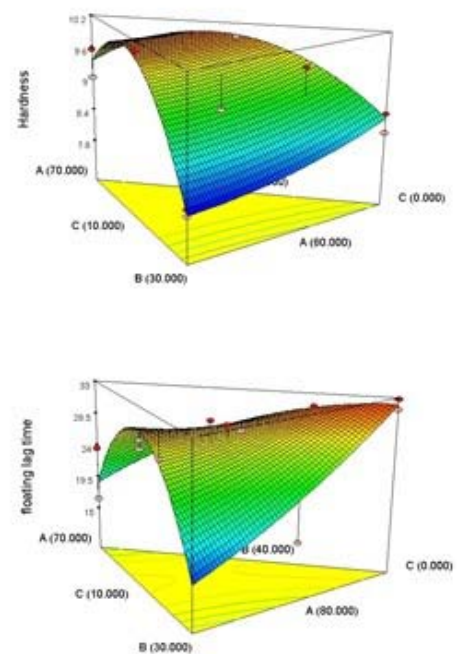

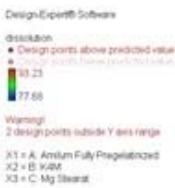

$\mathbf{E}$

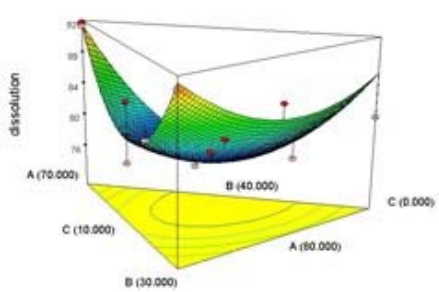

Fig. 5: Interaction factors A, B, and C on flow properties (A), interaction factors A, B, and C on hardness (B), Interaction factors A, B, and C on friability (C), Interaction factors A, B, and C on floating lag time (D), Interaction factors A, B, and C on dissolution (E)

\section{Optimization}

The selection of the optimum condition (fig. 6) is formula 1 , focused on the highest desirability value (table 8). The optimization process for NEFT has been evaluated by desirability value, the condition for optimum functional components in NEFT was $80 \mathrm{mg}$ for CSFP, HPMC K4M $30 \mathrm{mg}$, and $10 \mathrm{mg}$ magnesium stearate to obtain a yield of $7.85 \mathrm{~kg}$ hardness (fig. 5B), $0.34 \%$ friability (fig. 5C), 15.27 floating lag time (fig. 5D) and $91.31 \%$ ranitidine $\mathrm{HCl}$ dissolved (fig. 5E).
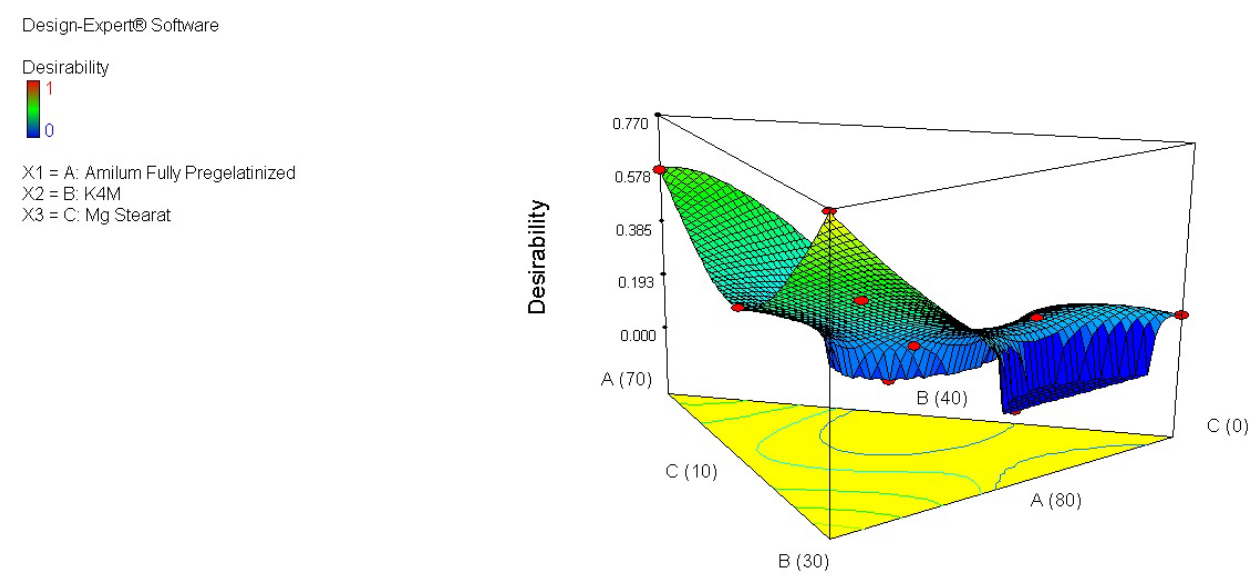

Fig. 6: Superimposed graphs of various contour plots 
Table 8: Solutions for 3 combinations of category factor levels

\begin{tabular}{lllllll}
\hline & CSFP(mg) & HPMC K4M (mg) & Magnesium stearate (mg) & Floating lag time (min) & Dissolution (\%) & Desirability \\
\hline 1 & 80 & 30 & 10 & 15.27 & 91.31 \\
2 & 70 & 40 & 10 & 19.73 & 89.77 \\
3 & 70 & 40 & 10 & 18.87 & 91.55 \\
4 & 79 & 39 & 2 & 30.88 & 82.66 \\
5 & 79 & 40 & 1 & 31.80 & 0.587 \\
\hline
\end{tabular}

*The selection of the optimum condition is formula 1, focused on the highest desirability value.

Table 9: Verification optimum formula

\begin{tabular}{llc}
\hline Response & Sample & p-value \\
\cline { 2 - 3 } & Experiment & Prediction \\
\hline Flow rate (g/s) \pm SD & $18.02+0.18$ & $17.84+0.15$ \\
Hardness (kg) \pm SD & $8.11+0.27$ & $7.85+0.35$ \\
Friability (\%) \pm SD & $0.32+0.02$ & $0.34+0.05$ \\
Floating lag time (min) \pm SD & $15.12+0.09$ & 0.44 \\
Dissolution (\%) \pm SD & $91.28+0.45$ & 0.38 \\
\hline
\end{tabular}

${ }^{*}$ The values are mean \pm standard deviation of $n=5$.

The experimental response data for the selected optimum formula was analyzed using the independent sample test for the T-test in the open state software to find out whether there was a difference in the response value of the SLD prediction. At the 95\% confidence level, the $p$-value for all responses is greater than 0.05 . This means that all response data have no significant difference in the response value of the SLD prediction. It can be concluded that between the verification data and predicted data statistically have no difference or have the same value.

\section{CONCLUSION}

The optimization process for NEFT has been evaluated by desirability value, the condition for optimum functional components in NEFT was $80 \mathrm{mg}$ for CSFP, HPMC K4M $30 \mathrm{mg}$, and $10 \mathrm{mg}$ magnesium stearate to obtain a yield of $7.85 \mathrm{~kg}$ hardness, $0.34 \%$ friability, 15.27 floating lag time and $91.31 \%$ ranitidine $\mathrm{HCl}$ dissolved.

\section{ACKNOWLEDGMENT}

This research was supported by Lembaga Pengelola Dana Pendidikan (LPDP) and Beasiswa Unggulan Dosen Indonesia-Dalam Negeri (BUDI-DN).

\section{CONFLICT OF INTERESTS}

The author declares there is no conflict of interest.

\section{AUTHORS CONTRIBUTIONS}

All author the author contributed equally

\section{REFERENCES}

1. Adedokun MO, Itiola OA. Disintegrant activities of natural and pregelatinized trifoliate yams, rice and corn starches in paracetamol tablets. J Appl Pharm Sci 2011;1:200-6.

2. Carstensen JT, Chan PC. Flow rate and angle of repose wet processed granulations. J Pharm Sci 1997;66:1238-5.

3. Olowosulu AK, Oyi A, Isah AB, Ibrahim MA. Formulation and evaluation of novel co-processed excipients of maize starch and acacia gum (StarAc) for direct compression tableting. Int J Pharm Res Innov 2011;2:39-45.

4. Qazi IM, Rakshit SK, Tran T, Ullah J, Khan Z. Effect of blending selected tropical starches on pasting properties of rice flour. Sarhad J Agric 2014;30:357-68.

5. Shastri DH, Patel LD, Parikh RK. Studies on in situ hydrogel: a smart way for safe and sustained ocular drug delivery. J Young Pharm 2010;2:116-20.

6. Achor M, Oyeniyi J, Musa M, Gwarzo M. Physicochemical properties of cassava starch retrograded in alcohol. J Appl Pharm Sci 2015;5:126-31.
7. Abdorreza MN, Robal M, Cheng LH, Tajul AY, Karim AA. Physicochemical, thermal, and rheological properties of acidhydrolyzed sago (Metroxylon sagu) starch. Food Sci Technol 2012;46:135-41.

8. Parwiyanti FP, Wijaya A, Malahayati N, Lidiasari E. Swelling power dan kelarutan pati ganyong (canna edulis, kerr.) termodifikasi melalui heat-moisture treatment dan penambahan gum xantan untuk produk roti; 2015. p. 692-9.

9. Patel VF, Patel NM. Intragastric floating drug delivery system of cefuroxime axetil: in vitro evaluation. AAPS PharmSciTech 2006; 7:E118-E124

10. Alhamdany AT, Abbas AK. Formulation and in vitro evaluation of amlodipine gastroretentive floating tablets using a combination of hydrophilic and hydrophobic polymers. Int J Appl Pharm 2018;10:119-25.

11. Cahyana A, Marzuki A. Analisa SEM (Scanning Electron Microscope) Pada Kaca TZN yang dikristalkan sebagian. Jur. Ilmu Fis. Pasca Sarj. Univ. Sebel. Maret 23; 2014.

12. Ansel. Pharmaceutical dosage form and drug delivery systems. Ninth. ed. University of Georgia; 2011.

13. Anwar E, Yusmarlina D, Rahmat H. Phosphorylation of pregelatinized maranta starch (Maranta arundinaceae L.) as theophylline tablet matrix controlled release. Indonesia J Pharm 2006;17:37-44.

14. Bahram HR, Hassan Beygi SR, Kianmehr MH, Valaei I, Mazraeh HM. The effect of moisture content, particle size and consolidation stress on flow properties of vermicompost. Agric Eng Int CIGR J 2014;247-52.

15. Bestari AN, Hidayatullah R, Sulaiman TNS. Pembuatan amilum sagu (Metroxylon sagu, Rottb.) pregelatin dan material komposit sebagai filler-binder sediaan tablet; 2016.

16. Bhardwaj TR, Kanwar M, Lal R, Gupta A. Natural gums and modified gums as sustained-release carriers. Drug Dev Ind Pharm 2000;26:1025-38.

17. Dewantara Putra, I Gusti Ngurah Agung. Physical and chemical properties of native and fully pregelatinized cassava starch (Manihot esculenta Crantz). Indonesian Journal of Pharmacy 2018;29:145-56.

18. Dreu R, Toschkoff G, Funke A, Altmeyer A, Knop K, Khinast J, Kleinebudde P. Evaluation of the tablets' surface flow velocities in pan coaters. Eur J Pharm Biopharm 2016;106:97-106.

19. El Mallawany R, Abdallah MD, Ahmed IA. New tellurite glass: optical properties. J Material Chem Physics 2008;109:291-6.

20. Emami J, Tavakoli N. Formulation of sustained-release lithium carbonate matrix tablets: influent of hydrophilic material on the release rate and in vitro-in vivo evaluation. Int J Pharm Pharm Sci 2004;15:338-44.

21. Gusnimar A. Teknik analisis kadar amilosa dalam beras. Bul Tek Pertan; 2003. p. 82-4. 
22. Hadi MA, Raghavendra RNG, Srinivasa RA. Formulation and evaluation of ileo-colonic targeted matrix-mini-tablets of naproxen for chronotherapeutic treatment of rheumatoid arthritis. Saudi Pharm J 2016;24:64-73.

23. Hastuti M. Pengaruh perbedaan suhu dalam metode pembuatan amilum singkong pregelatinasi terhadap sifat fisik tablet chlorpheniramine maleate secara kempa langsung. Universitas Muhammadiyah Surakarta; 2009.

24. Horwitz W. AOAC International (Eds.). Official methods of analysis of AOAC International. 18 ed. current through rev. 1 ed. AOAC International. Gaithersburg Md; 2006.

25. Indonesian Pharmacopeia. V. ed. Indonesia; 2014.

26. Juliano BO. A simplified assay for milded rice amylose. Cereal Sci Today 1971;16:334-60

27. Kemp SE, Hollywood T, Hort J. Sensory evaluation: a practical handbook. Ames, Iowa: Wiley-Blackwell, Chichester, U. K.; 2009.

28. Kim S, Limpongsa E, Jaipakdee N. Effects of formulation parameters on properties of gastric floating tablets containing poorly soluble drug: diclofenac sodium. Int J Appl Pharm 2018;10:152-60.

29. Niharika MG, Krishnamoorthy K, Akkala M. Overview on floating drug delivery system. Int J Appl Pharm 2018;3:65-71.

30. NMP, SSC, SV, CPA, Ras N. Formulation and evaluation of simvastatin gastroretentive drug delivery system. Int J Appl Pharm 2017;9:55-60.

31. Octavia MD, Halim A, Indriyani R. Pengaruh besar ukuran partikel terhadap sifat-sifat tablet metronidazol; 2017.

32. Onyango C, Mewa EA, Mutahi AW, dan Okoth MW. Effect of heat-moisture-treated cassava starch and amaranth malt on the quality of sorghum-cassava-amaranth bread. Afr J Food Sci 2013;7:80-6.
33. Piotrowski D, Golos A, Grzegory P. Shrinkage and mechanical properties of defrosted strawberries dried by convective, vacuum and convective-vacuum methods. Acta Agrophysica 2014;21:193-204.

34. Piyachomkwan K, Chotineeranat S, Kijkhunasatian C, Tonwitowat R, Prammanee S, Oates CG, et al. Edible canna (Canna edulis) as a complimentary starch source to cassava for the starch industry. Industrial Crops Products 2002;16:11-21.

35. Siswanto A, Soebagyo SS. Optimasi formula sediaan tablet lepas lambat teofilin dengan bahan matrik HPMC, Na CMC, dan xanthan gum. Maj Farm Indonesia 2006;17:143-8.

36. Sulaiman TNS, Fudholi A, Nugroho AK. Optimasi formula tablet gastroretentive ranitidine $\mathrm{HCl}$ dengan system floating. Majalah Farmasi Indonesia 2011;22:106-14.

37. United States Pharmacopeial Convention. The United States Pharmacopeia: the national formulary; 2014

38. Williams PCK. A rapid colorimetric procedure for estimating the amylose content of starch and flour; 1958.

39. Wlodarski K., Tajber L, Sawicki W. Physicochemical properties of direct compression tablets with spray dried and ball milled solid dispersions of tadalafil in PVP-VA. Eur J Pharm Biopharm 2016;109:14-23.

40. Yusif RM, Hashim IIA, Mohamed EA, El Rakhawy MM Investigation and evaluation of an in situ interpolymer complex of carbopol with polyvinylpyrrolidone as a matrix for gastroretentive tablets of ranitidine hydrochloride. Chem Pharm Bull Tokyo 2016;64:42-51.

41. Yusuf H, Radjaram A, Setyawan D. Modifikasi pati singkong pregelatin sebagai bahan pembawa cetak langsung. J Penelit Med Eksakta 2008;7:31-47. 